\title{
Investigação das manifestações patológicas no prédio de uma unidade de saúde na cidade de Gravatá-PE
}

\author{
A. J. Bento ${ }^{1 *}$, D. C. M. Neves ${ }^{1}$, E. C. B. Monteiro ${ }^{1,2}$ \\ *Contato do autor: adegilsonjose19@gmail.com \\ ${ }^{1}$ Escola Politécnica de Pernambuco, Universidade de Pernambuco, Recife, Brasil \\ ${ }^{2}$ Universidade Católica de Pernambuco, Recife, Brasil
}

\begin{abstract}
RESUMO
A manutenção predial é essencial durante o uso das edificações e a conservação das unidades de saúde é de suma importância para o bem estar da população. O objeto de estudo deste artigo teve sua construção iniciada em 2012 com recursos da Política Nacional de Urgência e Emergência, lançada pelo Ministério da Saúde, e ao longo desses 8 anos apresentou diversas manifestações patológicas, fruto principalmente da ausência de manutenção e da falta de uso da edificação. Este trabalho teve o intuito de identificar e avaliar os problemas presentes no prédio atualmente desativado de uma unidade de saúde do município de Gravatá. Como metodologia foram adotadas o que estabelecem a Norma de Inspeção Predial (Instituto Brasileiro de Avaliações e Perícias de Engenharia, Entidade Nacional - IBAPE, 2012) e da Norma de Manutenção em Edificações (Associação Brasileira de Normas Técnicas - ABNT, 2012) seguindo as etapas de: levantamento das informações pertinentes sobre o edifício, inspeção visual e registro fotográfico e elaboração de quadros para classificação das manifestações. Como resultado do trabalho, foram identificadas diversas manifestações patológicas, tais como: alvenaria (umidade ascendente e trincas e fissuras), pintura (descascamento e sujidades), forros (quebras e sujidades), revestimento cerâmicos (sujidades e quebras), esquadrias (possui apenas contramarco) e cobertura (sujidades, quebras e infiltração). Concluiu-se que há prioridade na manutenção da cobertura, das alvenarias e da pintura, em seguida realizando os reparos nas quebras de forro e revestimento cerâmico e finalizando com a eliminação das sujidades.
\end{abstract}

Palavras-chave: Inspeção; Manifestação patológicas; Unidade de saúde; IBAPE. 


\section{INTRODUÇÃO}

Segundo a NBR 5674 (ABNT, 2012), manutenção predial pode ser definida como o conjunto de ações a serem realizadas para conservar ou recuperar o funcionamento da edificação e dos seus elementos construtivos, buscando atender a segurança e as necessidades de uso de seus usuários. Já segundo o Instituto Brasileiro de Avaliação e Perícias em Engenharia (IBAPE, 2012), a inspeção predial tem por finalidade constatar as condições de segurança, funcionalismo, atuação, conservação, manutenção e operação de prédios e seus sistemas, além de atribuir criticidade às falhas e anomalias identificadas, sendo a análise isolada ou combinada das condições técnicas, de uso e de manutenção da edificação.

Independentemente do tipo de ocupação de um imóvel, ao longo dos anos é essencial executar a manutenção predial em todas as suas fases, garantindo assim sua vida útil. Para Gomide (2020), a inspeção predial trata-se de uma descrição técnica da qualidade da edificação que busca identificar as medidas de correção ou melhoria a fim de assegurar o bom funcionamento da construção. Principalmente se tratando de Unidades de saúde, que prestam um serviço essencial a população e sua ausência ou falta de pleno atendimento podem acabar acarretando em perdas fatais.

Fernandes e Ferreira (2018), observaram grande ocorrência de fissura, mofo, mancha de umidade, descolamento do reboco e bolhas na pintura nas unidades de saúde analisadas. Como possíveis causas, listam falhas na impermeabilização, escolha ineficaz dos materiais e problemas nas especificações em projeto. Já Silva e Leão (2019) encontraram infiltrações, trincas e deslocamento de revestimento, com possível causa em problemas estruturais e falhas no sistema de captação de água e na impermeabilização.

Na cidade de Gravatá, no agreste Pernambucano, as obras de um centro de especialidades hospitalares foram iniciadas em 2013, porém a unidade não foi inaugurada, ficando exposta a intempéries e vandalismo ao longo dos anos. Para retomar a construção, a realização de uma inspeção predial foi necessária para averiguar as manifestações patológicas presentes na edificação, sejam elas devido a anomalias construtivas ou falhas de manutenção.

Nesse contexto, visando a importância sobre medidas de avaliações preventivas, a importância que a inspeção predial apresenta na área da construção civil, um mecanismo capaz de avaliar as condições das edificações e ponto de partida para geração de um plano futuro para manutenção, este artigo tem como objetivo apresentar os resultados da inspeção predial na edificação com base nas diretrizes da Norma de Inspeção Predial (IBAPE, 2012) e da Norma de Manutenção em Edificações NBR 5674 (ABNT, 2012).

\section{METODOLOGIA}

\subsection{Critério Utilizado ${ }^{1}$}

A inspeção predial está baseada no "check-up" da edificação, que tem como resultado a análise técnica do fato ou da condição relativa à habitabilidade, mediante a verificação "in loco" de cada sistema construtivo, estando a mesma voltada para o enfoque da segurança e da manutenção predial, de acordo com as diretrizes da Norma de Inspeção Predial (IBAPE, 2012) e da Norma de Manutenção em Edificações (ABNT, 2012)

A inspeção procede ao diagnóstico das anomalias construtivas e falhas de manutenção que interferem e prejudicam o estado de utilização do prédio e suas instalações, tendo como objetivo verificar os aspectos de desempenho, vida útil, utilização e segurança que tenham interface direta com os usuários.

${ }^{1}$ Não foram realizados testes, medições ou ensaios por ocasião das vistorias, consoante o nível de inspeção estabelecido como escopo para este trabalho 


\subsection{Nível de Inspeção}

Esta inspeção é classificada como "Inspeção de Nível 1", representada por análise expedita dos fatos e sistemas construtivos vistoriados, com a identificação de suas anomalias e falhas aparentes.

Caracteriza-se pela verificação isolada ou combinada das condições técnicas de uso e de manutenção do sistema da edificação, de acordo com a Norma de Inspeção Predial do IBAPE, respeitado o nível de inspeção adotado, com a classificação das deficiências encontradas quanto ao grau de risco que representa em relação à segurança dos usuários, à habitabilidade e à conservação do patrimônio edificado.

\subsection{Grau de Risco}

Conforme a referida Norma de Inspeção Predial do IBAPE, as anomalias e falhas são classificadas em três diferentes graus de recuperação, considerando o impacto do risco oferecido aos usuários, ao meio ambiente e ao patrimônio.

\subsubsection{Grau de risco crítico - impacto irrecuperável}

É aquele que provoca danos contra a saúde e segurança das pessoas e meio ambiente, com perda excessiva de desempenho e funcionalidade, causando possíveis paralisações, aumento excessivo de custo, comprometimento sensível de vida útil e desvalorização imobiliária acentuada.

\subsubsection{Grau de risco regular - impacto parcialmente - recuperável}

É aquele que provoca a perda parcial de desempenho e funcionalidade da edificação, sem prejuízo à operação direta de sistemas, deterioração precoce e desvalorização em níveis aceitáveis.

\subsubsection{Grau de risco mínimo - impacto recuperável}

É aquele causado por pequenas perdas de desempenho e funcionalidade, principalmente quanto à estética ou atividade programável e planejada, sem incidência ou sem a probabilidade de ocorrência dos riscos relativos aos impactos irrecuperáveis e parcialmente recuperáveis, além de baixo ou nenhum comprometimento do valor imobiliário.

\subsection{Classificação das Irregularidades}

As recomendações técnicas para correção das anomalias, falhas de uso, operação ou manutenção e/ou não conformidades com a documentação analisada, foram organizadas em patamares de urgência. Utilizando o método GUT (gravidade, urgência e tendência) foi estabelecida uma matriz de prioridade para servir de guia para o planejamento da manutenção. Desenvolvida inicialmente para definir prioridades em atividades do setor administrativo, trata-se de uma ferramenta que pode ser utilizada para determinar a ordem de solução de problemas de acordo com a gravidade, urgência e tendência (LIMA, 2019).

\subsection{Documentação Analisada}

Os documentos técnicos disponibilizados para análise e consulta foram os seguintes:

- Levantamento Físico - Plantas Baixas dos Pavimentos

- Projeto Básico Hidrossanitário - Rede de Esgoto

- Projeto Básico Elétrico 


\subsection{Sistemas construtivos inspecionados}

Os seguintes sistemas construtivos foram inspecionados em seus elementos aparentes:

- Vedação e Alvenarias - Revestimentos e Fachadas;

- Instalações Elétricas - Entrada de Energia

- Instalações Hidros sanitárias - Reservatórios, Sanitários e Redes de Esgoto;

- Cobertura e Impermeabilização;

Os sistemas são relatados genericamente, seguindo-se a descrição e localização das anomalias e falhas detectadas, com a classificação do grau de risco atribuído a cada sistema: Grau Crítico, Grau Regular ou Grau Mínimo, excluída a criticidade das obras em andamento e/ou paralisadas.

\subsection{Identificação}

O prédio é constituído por dois pavimentos e várias salas para recepção, consultórios médicos, salas de exames e setor administrativo.

A edificação possui uma área construída de $856,75 \mathrm{~m} 2$, que se encontra assentada sobre um terreno com área superficial de aproximadamente $1036,83 \mathrm{~m} 2$, apresentando as seguintes características construtivas: estrutura de concreto armado sobre fundações em sapata, elevações em alvenaria de tijolos maciços com revestimento argamassado, cobertura em laje de concreto armado e telha cerâmica, esquadrias de vidro, pavimentação em piso de concreto e granilite e instalações prediais própria para a finalidade.

A Figura 1 e Figura 2 ilustram a edificação.

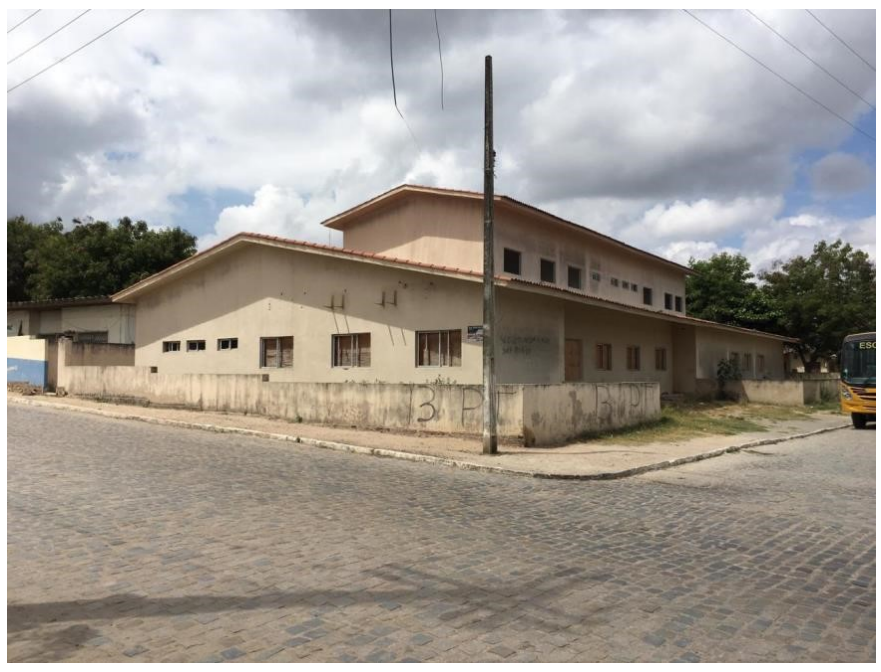

Figura 1. Vista frontal da edificação.

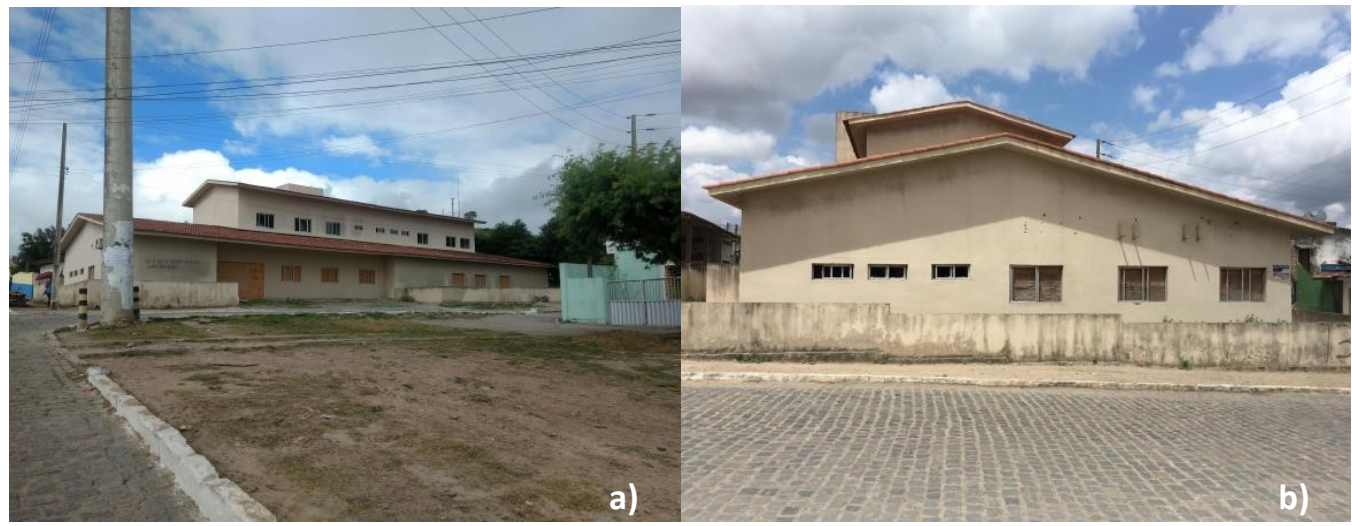

Figura 2. Fachadas a) principal e b) lateral esquerda. 


\subsection{Data da vistoria}

As vistorias técnicas nas dependências foram realizadas nos dias 18 e 19 de novembro de 2019, durante a manhã.

\subsection{Características}

Quadro 1. Características da construção.

\begin{tabular}{|c|c|}
\hline DESCRIÇÃO & ÁREAS (M²) \\
\hline Área do Terreno & 1036,83 \\
\hline Área Construída - Térreo & 628,05 \\
\hline Área Construída - $1^{\circ}$ Pav. & 228,70 \\
\hline Área Total & 856,75 \\
\hline Área de Coberta & 722,40 \\
\hline Área de Solo Natural & 275,98 \\
\hline
\end{tabular}

\section{RESULTADO E DISCUSSÕES}

Apresenta-se a relação das dependências dos setores vistoriados do prédio localizado na Rua Quatorze de Julho, tais como: recepção, consultórios médicos, salas de exames e setor administrativo, conforme segue:

Quadro 1. Ambientes do $1^{\circ}$ andar da edificação

\begin{tabular}{|c|c|}
\hline AMBIENTE & ÁREA (m $\mathbf{~}$ \\
\hline Repouso masculino & $10,40 \mathrm{~m} 2$ \\
\hline Repouso feminino & $15,40 \mathrm{~m} 2$ \\
\hline Direção & $13,38 \mathrm{~m} 2$ \\
\hline Almoxarifado & $13,32 \mathrm{~m} 2$ \\
\hline Arquivo médico & $11,93 \mathrm{~m} 2$ \\
\hline BWC feminino 2 & $6,51 \mathrm{~m} 2$ \\
\hline BWC masculino 2 & $6,51 \mathrm{~m} 2$ \\
\hline Hall & $6,88 \mathrm{~m} 2$ \\
\hline DML & $3,00 \mathrm{~m} 2$ \\
\hline Vestiário masculino & $5,60 \mathrm{~m} 2$ \\
\hline Vestiário feminino & $6,46 \mathrm{~m} 2$ \\
\hline Almoxarifado / material de limpeza & $2,96 \mathrm{~m} 2$ \\
\hline Despensa & $5,69 \mathrm{~m} 2$ \\
\hline Administração informática controle & $16,02 \mathrm{~m} 2$ \\
\hline C.P.D & $20,80 \mathrm{~m} 2$ \\
\hline Refeitório funcionários & $43,31 \mathrm{~m} 2$ \\
\hline Estar & $8,38 \mathrm{~m} 2$ \\
\hline Cantina dos pacientes & \\
\hline &
\end{tabular}


Quadro 2 - Ambientes do térreo da edificação.

\begin{tabular}{|c|c|}
\hline AMBIENTE & ÁREA (m \\
\hline Resíduos 1 \\
\hline Resíduos 2 & $3,50 \mathrm{~m} 2$ \\
\hline Sanitário masculino & $3,50 \mathrm{~m} 2$ \\
\hline Sanitário feminino & $1,66 \mathrm{~m} 2$ \\
\hline WC PPNE & $1,66 \mathrm{~m} 2$ \\
\hline Exames diferenciados & $3,60 \mathrm{~m} 2$ \\
\hline Exames indiferenciados & $11,85 \mathrm{~m} 2$ \\
\hline Prontuário & $11,84 \mathrm{~m} 2$ \\
\hline Atendimento & $2,21 \mathrm{~m} 2$ \\
\hline Recepção & $16,28 \mathrm{~m} 2$ \\
\hline Aplicação de medicamentos & $20,00 \mathrm{~m} 2$ \\
\hline
\end{tabular}

\subsection{Ocorrência das Manifestações patológicas:}

Quadro 4-Ocorrência das Manifestações patológicas (continua)

\begin{tabular}{|c|c|c|}
\hline \multicolumn{3}{|c|}{ Alvenaria } \\
\hline Manifestações patológicas & Ocorrências & Local \\
\hline Umidade ascendente & Todos. & Todos. \\
\hline Manchas & Não tem. & Não tem. \\
\hline Trincas e fissuras & 21 & $\begin{array}{c}\text { Repouso masculino; } \\
\text { Arquivo médico; } \\
\text { Administração informática; } \\
\text { Refeitório funcionário; } \\
\text { Cantina de pacientes e } \\
\text { circulação. }\end{array}$ \\
\hline Infiltração & Não tem. & Não tem. \\
\hline \multicolumn{3}{|c|}{ Pintura } \\
\hline & Ocorrências & Local \\
\hline Descascamento & Todos. & Todos. \\
\hline Bolhas & Não tem. & Não tem. \\
\hline Manchas & Não tem. & Não tem. \\
\hline Sujidades & Todos. & Todos. \\
\hline Sem pintura & Não tem. & Não tem. \\
\hline
\end{tabular}


Quadro 4 - Ocorrência das Manifestações patológicas (continuação)

\begin{tabular}{|c|c|c|}
\hline \multicolumn{3}{|c|}{ Forros } \\
\hline Manifestações patológicas & Ocorrências & Local \\
\hline Abaulamento & Não tem. & Não tem. \\
\hline Quebras & 20 & $\begin{array}{c}\text { Circulação; Sala de } \\
\text { urgência; Sala de } \\
\text { observação; Sala de } \\
\text { observação infantil; Quarto; } \\
\text { Sala de enfermagem; BWC } \\
\text { PPNE; Radiologia; Sala de } \\
\text { gesso; Inalação coletiva; } \\
\text { Sutura e curativo; } \\
\text { Aplicação e medicamentos; } \\
\text { Sala de ECG; Recepção; } \\
\text { Assistência social; Exames } \\
\text { indiferenciados; } \\
\text { Classificação de risco; } \\
\text { Atendimento; Vestiário } \\
\text { feminino e circulação. }\end{array}$ \\
\hline Sujidades & Todos. & Todos. \\
\hline \multicolumn{3}{|c|}{ Revestimento cerâmicos } \\
\hline Manifestações patológicas & Ocorrências & Local \\
\hline Sujidades & Todos. & Todos. \\
\hline Aderência & Possui aderência. & Todos. \\
\hline Quebras & 2 & $\begin{array}{c}\text { Distribuição de materiais } \\
\text { esterilizado e sanitário } \\
\text { masculino. }\end{array}$ \\
\hline Desgaste & Não tem. & Não tem. \\
\hline \multicolumn{3}{|c|}{ Instalações elétricas } \\
\hline Manifestações patológicas & Ocorrências & Local \\
\hline Caixas de passagem & Não tem. & Não tem. \\
\hline Tomadas/interruptores & Não tem. & Não tem. \\
\hline Disjuntores & Não tem. & Não tem. \\
\hline Sujidades & Não tem. & Não tem. \\
\hline Instalações (fios) & Não tem. & Não tem. \\
\hline \multicolumn{3}{|c|}{ Esquadrias } \\
\hline Manifestações patológicas & Ocorrências & Local \\
\hline Conservação & Possui apenas contramarco. & Todos. \\
\hline Funcionamento & Não tem. & Não tem. \\
\hline \multicolumn{3}{|c|}{ Cobertura } \\
\hline & Ocorrências & Local \\
\hline Sujidades & Todos. & Todos. \\
\hline Quebras & Vários pontos $(30 \%)$. & Vários pontos $(30 \%)$. \\
\hline Infiltração & Vários pontos $(30 \%)$. & Vários pontos $(30 \%)$. \\
\hline
\end{tabular}

\subsection{Alvenaria}


Quadro 5 - Caracterização de pontos com umidade.

\begin{tabular}{|c|l|}
\hline \multicolumn{3}{|c|}{ Umidade ascendente } \\
\hline \multicolumn{2}{|c|}{ Circulação 2} \\
\hline Sintoma & $\begin{array}{l}\text { Presença de umidade ascendente próximas ao piso nas paredes } \\
\text { internas. }\end{array}$ \\
\hline Mecanismo provável & Ascenção capilar da umidade. \\
\hline Causa provável & Umidade. \\
\hline Origem provável & Projeto arquitetônico/ Erro durante a execução. \\
\hline Classificação & Anomalia endógena. \\
\hline Grau de risco & Regular. \\
\hline Recomendações & $\begin{array}{l}\text { Remover o revestimento contaminado e realizar o reparo e a } \\
\text { impermeabilização da área ou fazer um corte horizontal o mais } \\
\text { próximo possível do piso e aplicar argamassa impermeabilizante. }\end{array}$ \\
\hline
\end{tabular}

Quadro 6 - Caracterização de fissuras nas esquadrias.

\begin{tabular}{|c|l|}
\hline \multicolumn{3}{|c|}{ Trincas e Fissuras } \\
\hline Ao lado da central 1 andar \\
\\
\\
\hline Sintoma & $\begin{array}{l}\text { Fissuras ao redor de aberturas de portas e janelas em paredes de } \\
\text { alvenaria. } 1 \text { andar }\end{array}$ \\
\hline Mecanismo provável & Acúmulo de tensões de tração nas aberturas. \\
\hline Causa provável & Armadura de reforço insuficiente. \\
\hline Origem provável & Projeto/Execução da armadura de reforço. \\
\hline Classificação & Anomalia endógena. \\
\hline Grau de risco & Regular. \\
\hline Recomendações & $\begin{array}{l}\text { Reforço da armadura ao redor das aberturas, com uso de vergas e } \\
\text { contravergas. }\end{array}$ \\
\hline
\end{tabular}

\subsection{Pintura}


Quadro 7 - Caracterização de pontos com descascamento da pintura

\begin{tabular}{|c|l|}
\hline \multicolumn{2}{|c|}{ Descascamento } \\
\hline \multicolumn{2}{|c|}{ Depósito } \\
\hline
\end{tabular}

Quadro 8 - Caracterização de pontos com umidade.

\begin{tabular}{|c|c|}
\hline \multicolumn{2}{|c|}{ Sujidades } \\
\hline & \\
\hline & \\
\hline Sintoma & Sujidades nas paredes internas da edificação. \\
\hline Mecanismo provável & Ação antrópica. \\
\hline Causa provável & Manutenção. \\
\hline Origem provável & Utilização. \\
\hline Classificação & Anomalia endógena. \\
\hline Grau de risco & Mínimo. \\
\hline Recomendações & Refazer a pintura. \\
\hline
\end{tabular}

\subsection{Forros}


Quadro 9 - Caracterização de pontos do forro com avarias.

\begin{tabular}{|c|l|}
\hline \multicolumn{2}{|c|}{ Quebras } \\
\hline Circulação 2,1 andar \\
\hline
\end{tabular}

Quadro 10 - Caracterização de pontos do forro com sujidades.

\begin{tabular}{|c|c|}
\hline \multicolumn{2}{|c|}{ Sujidades } \\
\hline \multicolumn{2}{|c|}{ Recepção } \\
\hline \\
\\
\\
\\
\hline Sintoma & Possui forros sujos em vários ambientes do edifício. \\
\hline Mecanismo provável & Ação antrópica e falta de manutenção. \\
\hline Causa provável & Manutenção. \\
\hline Origem provável & Utilização. \\
\hline Classificação & Anomalia endógena. \\
\hline Grau de risco & Mínimo. \\
\hline Recomendações & Reparo do forro com limpeza e pintura. \\
\hline
\end{tabular}

3.5 Revestimentos Cerâmicos 
Quadro 11 - Caracterização de paredes com revestimento cerâmico com sujidades.

\begin{tabular}{|c|c|}
\hline \multicolumn{2}{|c|}{ Sujidades } \\
\hline WC 2 & \multicolumn{1}{|c|}{ WC 1 } \\
\hline & \\
& \\
\hline Sintoma & Há presença de sujidades nos revestimentos cerâmicos. \\
\hline Mecanismo provável & Falta de manutenção. \\
\hline Causa provável & Ação natural. \\
\hline Origem provável & Utilização. \\
\hline Classificação & Anomalia endógena. \\
\hline Grau de risco & Mínimo. \\
\hline Recomendações & $\begin{array}{l}\text { Limpeza manual do revestimento cerâmico com pano úmido ou } \\
\text { mecânica com jato de água. }\end{array}$ \\
\hline
\end{tabular}

Quadro 12 - Caracterização de paredes com revestimento cerâmico avariados.

\begin{tabular}{|c|l|}
\hline \multicolumn{3}{|c|}{ Quebras e ausência de placas } \\
\hline \multicolumn{2}{|c|}{ DML } \\
\hline \\
\hline Sintoma & Placas cerâmicas quebradas ou ausentes. \\
\hline Mecanismo provável & Ação antrópica e falta de manutenção. \\
\hline Causa provável & Manutenção. \\
\hline Origem provável & Utilização. \\
\hline Classificação & Anomalia endógena. \\
\hline Grau de risco & Regular. \\
\hline Recomendações & $\begin{array}{l}\text { Recolocação de peças danificadas e recomposição do rejunte. } \\
\text { Limpeza do revestimento. }\end{array}$ \\
\hline
\end{tabular}

\subsection{Instalações Elétricas}


Quadro 13 - Caracterização das instalações elétricas.

\begin{tabular}{|c|l|}
\hline \multicolumn{3}{|c|}{ Instalações, Tomadas/ Interruptores } \\
\hline \multicolumn{2}{|c|}{ Almoxarifado } \\
\hline \\
Sintoma & $\begin{array}{l}\text { Ausência de tomadas, interruptores, das fiações e presença de } \\
\text { instalações avariadas }\end{array}$ \\
\hline Mecanismo provável & Ação antrópica. \\
\hline Causa provável & Manutenção. \\
\hline Origem provável & Utilização. \\
\hline Classificação & Anomalia endógena. \\
\hline Grau de risco & Crítico. \\
\hline Recomendações & $\begin{array}{l}\text { Refazer as instalações elétricas repondo tomadas e interruptores } \\
\text { ausentes. }\end{array}$ \\
\hline
\end{tabular}

\subsection{Esquadrias}

Quadro 14 - Caracterização do estado de conservação das esquadrias

\begin{tabular}{|c|c|}
\hline \multicolumn{3}{|c|}{ Conservação e Funcionamento } \\
\hline \multicolumn{2}{|c|}{ Ao lado da central } \\
\hline \\
\hline Sintoma & Possui apenas o contramação 2 \\
\hline Mecanismo provável & Ação antrópica. \\
\hline Causa provável & Manutenção. \\
\hline Origem provável & Utilização. \\
\hline Classificação & Anomalia endógena. \\
\hline Grau de risco & Crítico. \\
\hline Recomendações & $\begin{array}{l}\text { Substituição dos contramarcos deteriorados, instalações dos } \\
\text { marcos e caixilhos das janelas e substituição dos batentes e } \\
\text { guarnições deterioradas e instalação das folhas. }\end{array}$ \\
\hline
\end{tabular}

3.8 Cobertura 
Quadro 15 - Caracterização do estado de conservação da coberta.

\begin{tabular}{|c|c|}
\hline \multicolumn{2}{|c|}{ Sujidades e quebras } \\
\hline \multicolumn{2}{|c|}{ Coberta } \\
\hline Sintoma & Possui sujidades nas telhas \\
\hline Mecanismo provável & Ação antrópica e falta de manutenção \\
\hline Causa provável & Manutenção. \\
\hline Origem provável & Utilização. \\
\hline Classificação & Anomalia endógena. \\
\hline Grau de risco & Mínimo. \\
\hline Recomendações & $\begin{array}{l}\text { Remoção das telhas cerâmicas, recuperação da estrutura de } \\
\text { madeira deteriorada, limpeza (lavagem) das telhas e retelhamento } \\
\text { com reposição das peças danificadas. }\end{array}$ \\
\hline
\end{tabular}

\subsection{CLASSIFICAÇÃO DAS IRREGULARIDADES}

Através da utilização da matriz GUT, foram estabelecidas as ordens de prioridade para solução das manifestações patológicas (Quadro 16). Desse modo, as primeiras manutenções devem ser realizadas na cobertura, nas alvenarias e na pintura, em seguida realizando os reparos nas quebras de forro e revestimento cerâmico e finalizando com a eliminação das sujidades.

Quadro 16 - Aplicação da matriz GUT (continua).

\begin{tabular}{|c|c|c|c|c|c|c|c|}
\hline Cód. & $\begin{array}{c}\text { Manifestação } \\
\text { Patológica }\end{array}$ & Elemento & $\begin{array}{c}\text { Gravidade } \\
(\mathbf{G})\end{array}$ & $\begin{array}{c}\text { Urgência } \\
(\mathbf{U})\end{array}$ & $\begin{array}{c}\text { Tendência } \\
(\mathbf{T})\end{array}$ & GxUxT & Ordem \\
\hline 1 & $\begin{array}{c}\text { Umidade } \\
\text { ascendente }\end{array}$ & Alvenaria & 5 & 4 & 5 & 100 & $2^{\circ}$ \\
\hline 2 & $\begin{array}{c}\text { Trincas e } \\
\text { fissuras }\end{array}$ & Alvenaria & 3 & 3 & 3 & 27 & $5^{\circ}$ \\
\hline 3 & Descascamento & Pintura & 5 & 4 & 3 & 60 & $4^{\circ}$ \\
\hline 4 & Sujidades & Pintura & 1 & 1 & 1 & 1 & $10^{\circ}$ \\
\hline 5 & Quebras & Forro & 3 & 3 & 1 & 9 & $7^{\circ}$ \\
\hline 6 & Sujidades & Forro & 1 & 1 & 1 & 1 & $11^{\circ}$ \\
\hline 7 & Sujidades & $\begin{array}{c}\text { Rev. } \\
\text { cerâmico }\end{array}$ & 2 & 1 & 1 & 2 & $9^{\circ}$ \\
\hline
\end{tabular}

Quadro 16 - Aplicação da matriz GUT (continuação). 


\begin{tabular}{|c|c|c|c|c|c|c|c|}
\hline Cód. & $\begin{array}{c}\text { Manifestação } \\
\text { Patológica }\end{array}$ & Elemento & $\begin{array}{c}\text { Gravidade } \\
(\mathbf{G})\end{array}$ & $\begin{array}{c}\text { Urgência } \\
(\mathbf{U})\end{array}$ & $\begin{array}{c}\text { Tendência } \\
(\mathbf{T})\end{array}$ & $\mathbf{G x U x T}$ & Ordem \\
\hline 8 & Quebras & $\begin{array}{c}\text { Rev. } \\
\text { cerâmico }\end{array}$ & 2 & 5 & 1 & 10 & $6^{\circ}$ \\
\hline 9 & Sujidades & Cobertura & 3 & 1 & 2 & 6 & $8^{\circ}$ \\
\hline 10 & Quebras & Cobertura & 4 & 5 & 3 & 60 & $3^{\circ}$ \\
\hline 11 & Infiltração & Cobertura & 5 & 5 & 5 & 125 & $1^{\circ}$ \\
\hline
\end{tabular}

Essa ordem mostra que os piores problemas estão relacionados a erros de execução e falta de manutenção, que fazem com que a água, um dos principais agentes causadores de manifestações patológicas, seja responsável por parte dos problemas encontrados.

\section{CONCLUSÃO}

Após a análise documental e vistoria do complexo, identificou-se que o empreendimento possui vícios de manutenção e alguns construtivos referentes à vedação e alvenarias - revestimentos e fachadas; instalações elétricas - entrada de energia; instalações hidros sanitárias - reservatórios, sanitários e redes de esgoto e cobertura e impermeabilização.

No presente caso não existe plano de manutenção no empreendimento, devendo ser verificado as atividades de manutenção realizadas e devidamente registradas (evidências), comparando-as com o conjunto de recomendações mínimas de fabricantes e fornecedores de equipamentos e sistemas inspecionados de modo a constatar se estão sendo atendidas.

São elementos observados no trabalho de inspeção predial, que devem ser considerados na classificação da qualidade de manutenção: falhas constatadas; não conformidades registradas nos documentos pertinentes à manutenção; classificações dos graus de risco; atendimento às necessidades da edificação, considerados os conceitos de desempenho, vida útil, durabilidade, observados os atendimentos aos demais aspectos mencionados na NBR 5674 (ABNT,2012)

Diante do exposto, entende-se haver urgente necessidade na construção de um Plano de Manutenção, bem como contratar os serviços de profissional ou empresa especializada para realizar a manutenção corretiva recomendada, de modo que seja atendido todos os requisitos exigidos nas normas vigentes. Devem ser priorizados os serviços de manutenção na cobertura, alvenarias e pintura, buscando eliminar com urgência as quebras, trincas e fissuras, posteriormente eliminando as outras manifestações patológicas.

Entende-se que os problemas encontrados na unidade de saúde podem vir a agravar intensamente as enfermidades e o bem estar dos usuários da edificação, seja acentuando doenças respiratórias devido à presença de umidade ou propiciando a ocorrência de acidentes. Portanto, é de suma importância a resolução destas questões antes da reabertura do estabelecimento ao público.

\section{REFERÊNCIAS}

Associação Brasileira de Normas Técnicas. (2012). NBR 5674: Manutenção de edificações Requisitos para o sistema de gestão de manutenção. Rio de Janeiro.

Fernandes, E. C.; Ferreira, V. (2018), “Investigação das manifestações patológicas incidentes nas edificações utilizadas como unidades básicas de saúde de Tubarão/SC”. Trabalho de conclusão de curso, Universidade do Sul de Santa Catarina, Tubarão.

Gomide, T. L. F., et al. (2020), “Inspeção Predial Total”. Oficina de Textos, $3^{\mathrm{a}}$ ed. 
Instituto Brasileiro de Avaliações e Perícias de Engenharia - IBAPE. (2012). Norma de inspeção predial nacional, São Paulo.

Lima, M. G. H. (2019), “Diagnóstico de incidências de manifestações patológicas com a utilização da metodologia matriz GUT - estudo de caso”. Monografia, Universidade Federal Rural do SemiÁrido, Mossoró.

Silva, D. C. Da; Leão, M. F. (2019), "Estudo das manifestações patológicas de uma unidade de saúde do município de Jaraguá-GO”. Trabalho de conclusão de curso, Faculdade Evangélica de Jaraguá, Jaraguá. 